\title{
Linkage between winter sea surface temperature east of Australia and summer precipitation in the Yangtze River valley and a possible physical mechanism
}

\author{
ZHOU BoTao \\ National Climate Center, China Meteorological Administration, Beijing 100081, China
}

Received January 31, 2011; accepted March 25, 2011; published online May 10, 2011

\begin{abstract}
The relationship between winter sea surface temperature (SST) east of Australia and summer precipitation in the Yangtze River valley and a possibly related physical mechanism were investigated using observation data. It is found that winter SST east of Australia is correlated positively to summer precipitation in the Yangtze River valley. When the SST east of Australia becomes warmer in winter, the western Pacific subtropical high and the East Asian westerly jet tend to shift southward the following summer, concurrent with low-level southwesterly anomalies over eastern China. These conditions favor precipitation increase in the Yangtze River valley, whereas the opposite conditions favor precipitation decrease. The influence of winter SST east of Australia on East Asian summer atmospheric circulations may occur in two ways. First, by an anomalous SST signal east of Australia in winter that persists through the following summer, thus affecting East Asian atmospheric circulations via the inter-hemispheric teleconnection. Second, when the SST east of Australia is warmer in winter, higher SST appears simultaneously in the southwest Indian Ocean and subsequently develops eastward by local air-sea interaction. As a result, the SST in the Maritime Continent increases in summer, which may lead to an anomalous change in East Asian summer atmospheric circulations through its impact on convection.
\end{abstract}

sea surface temperature east of Australia, summer precipitation, Yangtze River valley, teleconnection, physical mechanism

Citation: Zhou B T. Linkage between winter sea surface temperature east of Australia and summer precipitation in the Yangtze River valley and a possible physical mechanism. Chinese Sci Bull, 2011, 56: 1821-1827, doi: 10.1007/s11434-011-4497-9

Because of the influence of the East Asian summer monsoon, the Yangtze River valley in China often suffers from severe droughts and floods, resulting in serious losses to the economy and of human lives. Therefore, the interannual variability and predictability of summer precipitation in this region is of prime interest. The aim of this research is to improve understanding of the mechanisms of rainfall variation in the Yangtze River valley and to provide a scientific basis for short-term prediction.

Many studies in the past few years have sought antecedent signals that influence summer precipitation in the Yangtze River valley. For instance, Gong et al. [1,2] analyzed the impact of spring Arctic Oscillation on summer

email: zhoubt@cma.gov.cn rainfall in the Yangtze River valley. They found that a stronger (weaker) spring Arctic Oscillation is followed by a more northerly (southerly) East Asian jet and less (more) rainfall over the Yangtze River valley in summer, showing an out-of-phase relationship. Studies by Wang et al. [3,4] revealed that the Eurasian atmospheric anomaly in spring may play an important role in variations of the East Asian atmospheric circulation and precipitation in summer. Ground snow cover over the Tibetan Plateau in spring is also closely related to summer precipitation in the Yangtze River valley. An increase of spring snow cover can affect East Asian summer atmospheric circulations through changing soil moisture, consequently increasing precipitation in the Yangtze River valley [5]. Zhao et al. [6] pointed out that shrinkage (expansion) of spring sea ice extent in the 
Bering Sea and Okhotsk Sea can increase (decrease) summer rainfall over eastern China. Zhou et al. [7,8] demonstrated a significant positive correlation between the spring Hadley circulation and summer precipitation in the Yangtze River valley, based on observational analysis and numerical simulation. The Hadley circulation in spring affects summer rainfall in the Yangtze River valley mainly through its influence on the SST in the Indian Ocean and South China Sea. The winter Western Atlantic pattern (WA) [9] and the East Asian winter monsoon $[10,11]$ have also been shown to have a significant impact on summer precipitation in the Yangtze River valley.

The aforementioned research identified some antecedent signals in the Northern Hemisphere that affect summer precipitation in the Yangtze River valley. Because the Southern Hemisphere is one of original regions for the monsoon and a key region of global climate system, atmospheric anomalies there can certainly affect the East Asian summer monsoon, thereby causing droughts and floods in the Yangtze River valley. Antarctic Oscillation (AAO), which is the main atmospheric mode in the Southern Hemisphere, plays an important role in changes to the East Asian summer monsoon and precipitation in China [12-15]. When the AAO strengthened (weakened) in spring, summer precipitation tended to increase (decrease) in the Yangtze River valley. Gao et al. [16] showed that there is a longer period of Meiyu along the Yangtze and Huaihe River valley if the AAO in May is stronger. Fan et al. [17] applied the AAO as one significant predictor within a statistical forecast model for summer rainfall in the Yangtze River valley. Xue et al. $[12,18]$ discussed the role of spring subtropical highs in the Southern Hemisphere (i.e. the Mascarene high and the Australian high) in summer rainfall over the Yangtze River valley, finding a positive correlation between the two.

Therefore, atmospheric circulations in the Southern Hemisphere strongly impact upon East Asian summer monsoon circulations. Of course, SST changes can directly affect Southern Hemispheric circulations [19,20]. For example, Liu et al. [20] indicated that SST anomalies east of Australia may change the Australian High. Namely, high (low) SST east of Australia corresponds to a more eastward (westward) Australian high. Since a dominant component of hemispheric interaction is characterized by winter hemisphere influencing summer hemisphere, a question arises whether winter SST change east of Australia links to the East Asian summer atmospheric circulation, especially the summer precipitation in the Yangtze River. If so, what would be the physical mechanism responsible for such a link? The current study investigates these links and a possible physical mechanism.

\section{Data}

Data sets include: (1) atmospheric reanalysis data at $2.5^{\circ} \times$ $2.5^{\circ}$, provided by the National Centers for Environmental Prediction/National Center for Atmospheric Research (NCEP/NCAR) [21], (2) SST data at $2^{\circ} \times 2^{\circ}$ from the National Oceanic and Atmospheric Administration (NOAA) [22], and (3) Chinese 160-station monthly precipitation data derived from the China Meteorological Administration (CMA) for 1951-2002. In this study, winter (DJF) refers to December in the preceding year and January and February in the following year. Spring (MAM) refers to March, April and May, and summer (JJA) to June, July and August. The mean precipitation from 17 stations (Nanjing, Hefei, Shanghai, Hangzhou, Anqing, Tunxi, Jiujiang, Hankou, Zhongxiang, Yueyang, Yichang, Changde, Ningbo, Quxian, Guixi, Nanchang, Changsha) is defined as the Yangtze River rainfall index (YRRI), which represents the variation of precipitation in the Yangtze River valley.

\section{Winter SST east of Australia and summer precipitation in the Yangtze River valley}

Figure 1(a) displays the spatial distribution of correlation coefficients between winter SST and the summer YRRI. There are significant positive correlations in the region east of Australia, with maximum values exceeding 0.4. This implies that warmer (colder) SST east of Australia in winter corresponds to more (less) summer rainfall over the Yangtze River valley the following summer. To measure the

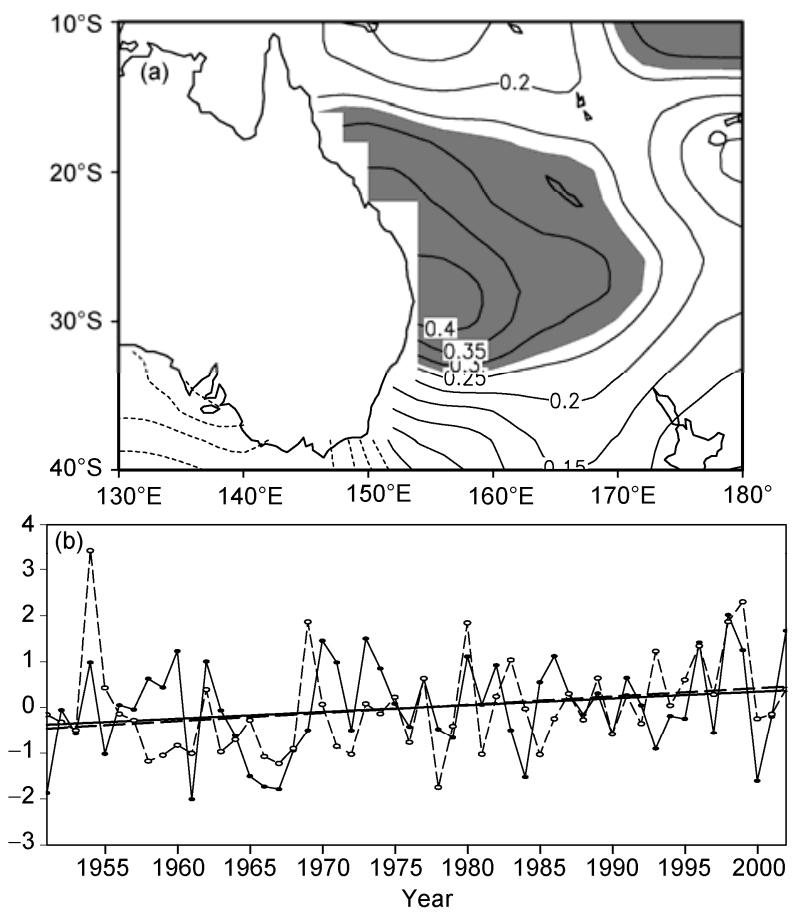

Figure 1 (a) Correlations between the summer YRRI and winter SST. Regions with results above the $95 \%$ significance level are shaded. (b) Time series of the normalized summer YRRI (dashed line) and winter EASST (solid line) and their respective linear trends. 
temporal variation of winter SST east of Australia, we defined an East of Australia SST index (EASST) as the regional mean SST within the significant region shown in Figure 1(a). The time series of the winter EASST and summer YRRI is presented in Figure 1(b), indicating an inphase relationship with a correlation coefficient of 0.4 , significant at the $99.9 \%$ level. Additionally, both indices exhibit an increasing linear trend with time. After filtering this linear trend, the two indices are still significantly correlated, with a correlation coefficient of 0.34 , well above the $95 \%$ significance level. Therefore, the link between winter SST east of Australia and summer precipitation in the Yangtze River valley is robust on the interannual timescale. Since we emphasize their relationship on the interannual timescale, the linear trends for the time series have been removed in the subsequent analysis.

To illustrate the large-scale atmospheric circulation underlying the in-phase relationship between winter SST east of Australia and summer precipitation in the Yangtze River valley, we analyzed the regression pattern of low-level winds in summer against the winter EASST and summer YRRI, respectively (Figure 2). In Figure 2(a), the horizontal winds at $700 \mathrm{hPa}$ in association with the summer YRRI show an anomalous anticyclonic circulation dominating the western Pacific south of $30^{\circ} \mathrm{N}$, with the easterly wind anomaly over the tropical monsoon trough region and the westerly wind anomaly over the Meiyu front region. This configuration indicates a more southward location of the western Pacific subtropical high. Moreover, anomalous southwesterly winds prevail over eastern China, conducive to water vapor transport from the tropics to the midlatitudes. This result is consistent with the finding of Zhang et al. [23]. Their study showed that summer precipitation in the Yangtze River valley tends to be above normal if an anticyclonic circulation anomaly emerges over the western Pacific south of $30^{\circ} \mathrm{N}$. The summer wind change in the lower troposphere associated with the winter EASST (Figure 2(b)) is generally similar to that presented in Figure 2(a). The anticyclonic circulation anomaly over the Western Pacific south of $30^{\circ} \mathrm{N}$ and the southwesterly wind anomaly over eastern China are also evident. The similarity between the two panels of Figure 2 suggests that warmer (colder) SST east of Australia in the preceding winter corresponds to a tendency for an anomalous anticyclonic (cyclonic) circulation in the western Pacific south of $30^{\circ} \mathrm{N}$ and a southward (northward) shift of the western subtropical high in summer. This circulation is favorable (unfavorable) for precipitation in the Yangtze River valley, thus increasing (decreasing) local precipitation in summer.

The East Asian westerly jet (EAJ), especially its location, has been known to play a dynamic role in the precipitation variability. A southward (northward) displacement of the EAJ often leads to wetter (drier) conditions in the Yangtze River valley [24,25]. This can be confirmed by the regression pattern between the YRRI and $200 \mathrm{hPa}$ zonal wind in
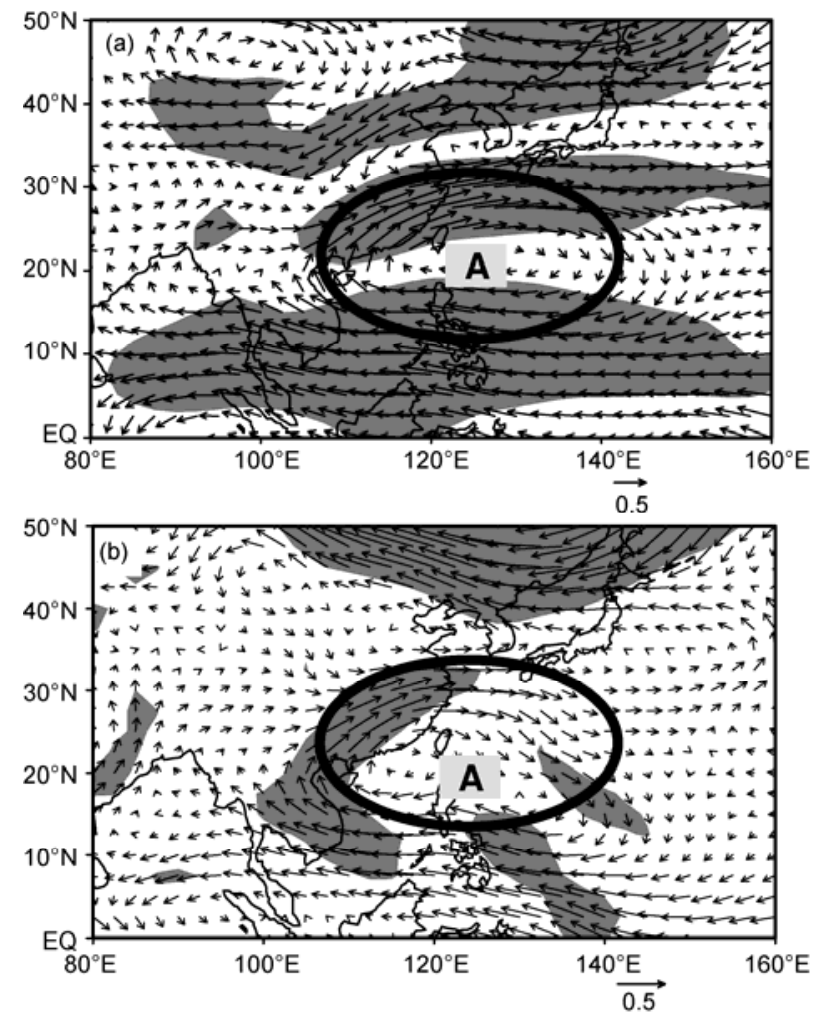

Figure 2 Regression of summer horizontal winds $(\mathrm{m} / \mathrm{s})$ at $700 \mathrm{hPa}$ against summer YRRI (a) and winter EASST (b). Regions with results above the $95 \%$ significance level are shaded. "A" indicates anticyclonic circulation.

summer. Figure 3(a) clearly shows that the high-level atmospheric circulation in relation to more precipitation over the Yangtze River valley corresponds to anomalous westerlies and easterlies to the south and north of $40^{\circ} \mathrm{N}$, respectively. This pattern is indicative of a southward displacement of the EAJ (the EAJ core is located near $40^{\circ} \mathrm{N}$ in the climatology). The regression pattern of $200 \mathrm{hPa}$ zonal wind in summer versus winter EASST (Figure 3(b)) resembles the pattern of Figure 3(a). With the positive phase of winter EASST, negative (positive) values appear north (south) of $40^{\circ} \mathrm{N}$, indicating a weakening (strengthening) of high-level westerlies and the southward shift of the EAJ in summer. This configuration is beneficial for precipitation increase in the Yangtze River valley. This result again supports the inphase relationship between winter SST east of Australia and summer precipitation in the Yangtze River valley.

\section{A possible physical mechanism}

Based on the above analysis, we can deduce that the winter SST change east of Australia can influence the East Asian atmospheric circulation the following summer, which in turn affects the interannual variation of precipitation in the Yangtze River valley. To address how the winter SST east of Australia affects the East Asian summer atmospheric 

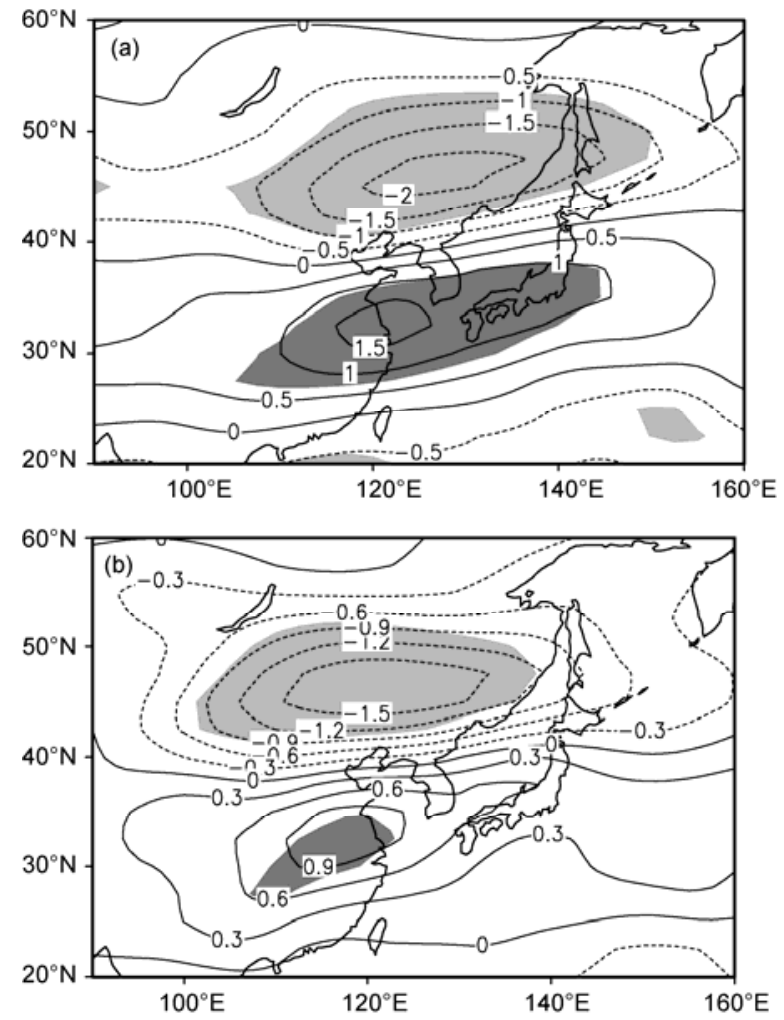

Figure 3 Regression of summer zonal winds (m/s) at $200 \mathrm{hPa}$ against summer YRRI (a) and winter EASST (b). Regions with results above the 95\% significance level are shaded.

circulation, we investigated correlations between the winter EASST and the SST in winter and subsequent spring and summer, respectively. The results are plotted in Figure 4. There are two pronounced features in this figure. One is the persistence of the SST signal east of Australia. The correlation coefficients in the region east of Australia are always significantly positive but decrease gradually from winter through summer. The other feature is the development and propagation of the South Indian Ocean SST. In winter, the EASST is significantly and positively correlated to the SST in the Southwest Indian Ocean. Afterwards, this significant positive correlation moves eastward and lies over the Maritime Continent the following summer.

Therefore, the winter SST east of Australia can affect summer atmospheric circulations and precipitation in two ways. On one hand, SST anomaly over the region east of Australia in winter can persist until the following summer because of its own long memory. This summer SST anomaly may influence rainfall in the Yangtze River valley by exciting an inter-hemispheric teleconnection [26]. If the SST east of Australia is higher (lower) in summer, the local geopotential height would become greater (lesser). Such a disturbance in geopotential height may propagate to the subtropical area of the Northern Hemisphere via a Rossby wave. This occurrence strengthens (weakens) the western Pacific subtropical high and extends it southward and westward (northward and eastward), hence increasing (de- creasing) precipitation in the Yangtze River valley [20,26]. On the other hand, when the winter SST east of Australia is higher (lower), the simultaneous SST also appears higher (lower) in the southwest Indian Ocean. Such an anomalous signal develops and moves gradually eastward with time and reaches the Maritime Continent in summer. The summer SST anomaly in the Maritime Continent can further affect the East Asian atmospheric circulation. Figure 5 depicts the correlation between divergence and the regional mean SST averaged in the region $90^{\circ}-140^{\circ} \mathrm{E}, 15^{\circ} \mathrm{S}-0^{\circ}$ (shown as the rectangle in Figure 4(c)) in summer. At 150 $\mathrm{hPa}$ (Figure 5(a)), there are significant positive correlations over the Maritime Continent and significant negative correlations over the western Pacific. The spatial distribution of the correlations at $1000 \mathrm{hPa}$ is reversed, with negative values over the Maritime Continent and positive values over the western Pacific (Figure 5(b)). This pattern suggests that when the SST is warmer in the Maritime Continent, anomalous high-level divergence and low-level convergence are dominant in this region, strengthening convection. In contrast, anomalous high-level convergence and low-level divergence are predominant over the western Pacific, especially east of Philippines, suppressing convection. This weakened convection has an impact on the summer atmos-
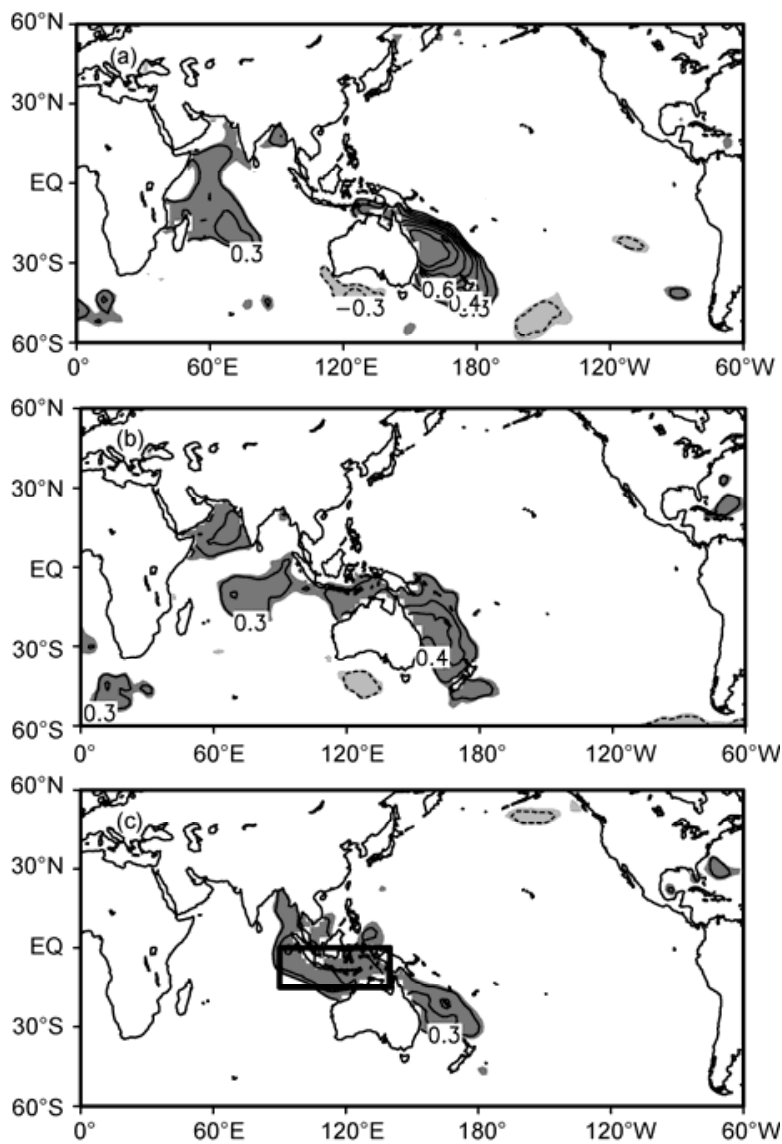

Figure 4 Correlations of the winter EASST with SST in winter (a), spring (b) and summer (c). Regions with results above the $95 \%$ significance level are shaded. 

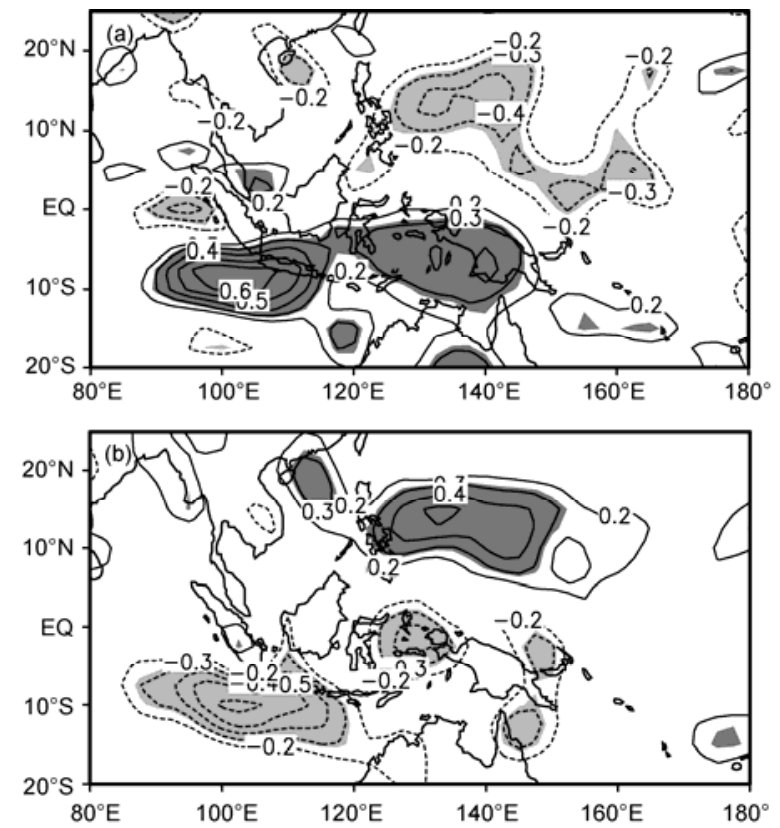

Figure 5 Correlations of the regional mean SST averaged in the region $90^{\circ}-140^{\circ} \mathrm{E}, 15^{\circ} \mathrm{S}-0^{\circ}$ with the divergence at $150 \mathrm{hPa}$ (a) and $1000 \mathrm{hPa}(\mathrm{b})$. Regions with results above the $95 \%$ significance level are shaded and only the absolute values exceeding 0.2 are shown.

pheric circulation and precipitation in the Yangtze River valley via the planetary-scale Pacific-Japan (PJ) teleconnection wave train $[27,28]$.

Hereafter we discuss the link between the SST east of Australia and that in the southwest Indian Ocean, based on a composite analysis. The criteria for determining positive (negative) cases are: 11 (8) years with the normalized, de-trended EASST greater (less) than $1(-1)$. Figure 6 shows the composite difference of $200 \mathrm{hPa}$ zonal wind in winter, between strong and weak EASST years. A wellorganized teleconnection pattern from the east flank of Australia to the South Africa-southwest Indian Ocean (shown by the thick dashed line) is notable. This teleconnection links the atmospheric circulation change in these two regions. Corresponding to warmer SST east of Australia in winter, an anomalous anticyclonic circulation east of Australia and an anomalous cyclonic circulation over South Africa and the southwest Indian Ocean appear in the upper troposphere, and vice versa.

The lower-tropospheric circulation over the southwest Indian Ocean adjusts according to the change in uppertropospheric circulation. As shown in Figure 7(a), a cyclonic circulation anomaly is dominant in the region east of Madagascar, and an anticyclonic circulation anomaly is predominant to its northeast. Studies have verified that wind-induced ocean dynamic processes (upwelling/downwelling and thermocline variation) impose a major control on SST variability in the southwest Indian Ocean [29-31]. Thus, anomalous surface winds in Figure 7(a) would significantly impact local SST variability. The wind curl on the

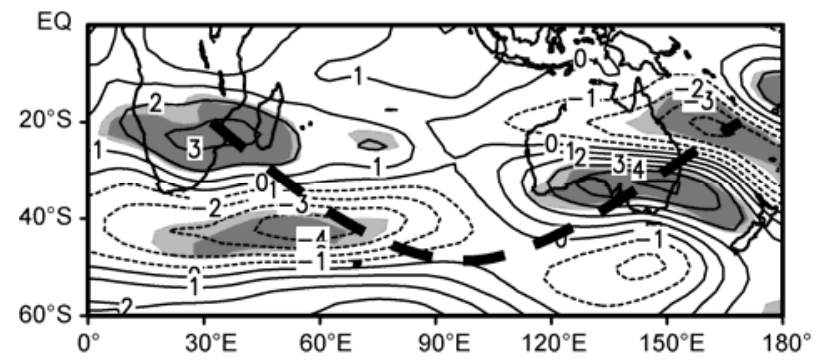

Figure 6 Composite difference of $200 \mathrm{hPa}$ zonal wind $(\mathrm{m} / \mathrm{s})$ in winter between strong and weak EASST years. Heavy (Light) shadings indicate regions with results above the $95 \%$ (90\%) significance level. Teleconnection pattern from the east flank of Australia to the South Africa-southwest Indian Ocean is shown by the thick dashed line.
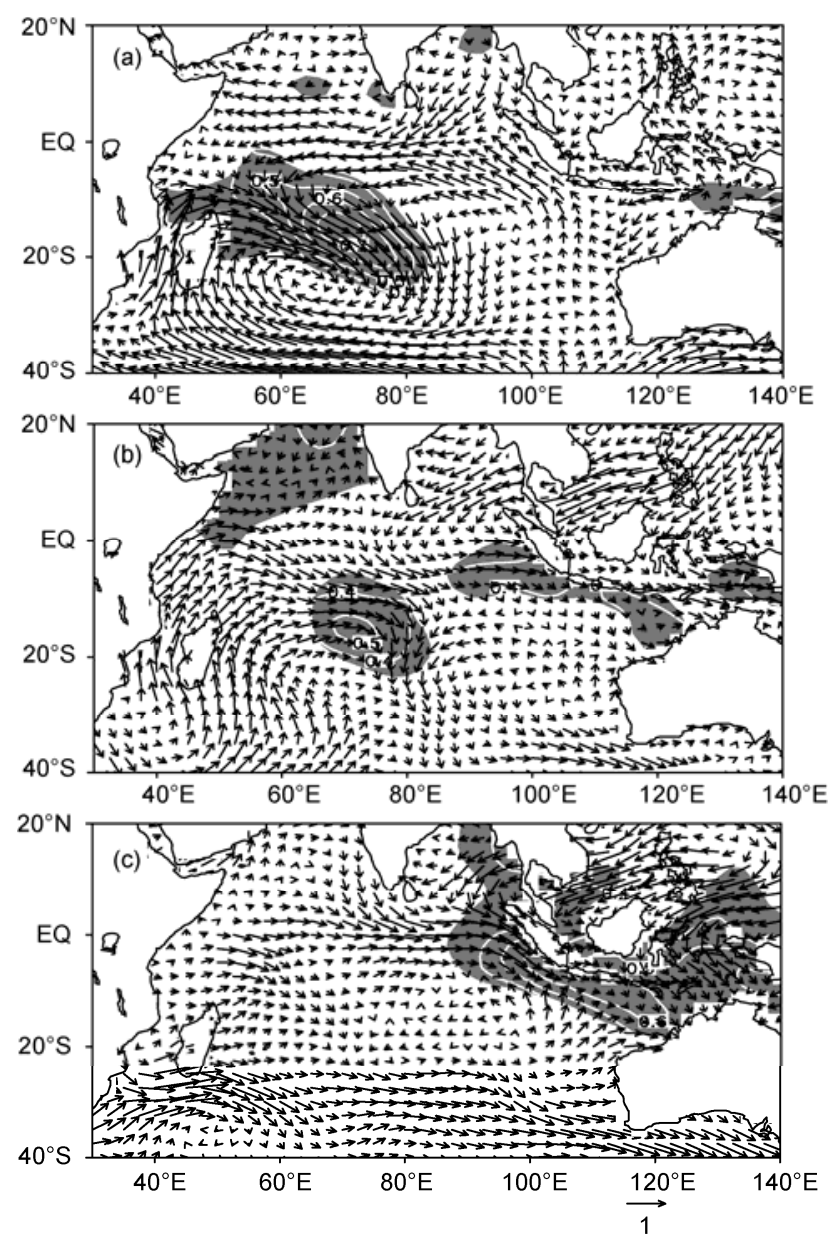

Figure 7 Composite difference of surface wind (vectors, $\mathrm{m} / \mathrm{s}$ ) and SST (contours, ${ }^{\circ} \mathrm{C}$ ) between strong and weak EASST years. (a) winter, (b) spring, (c) summer. Regions where SST difference results are above the $95 \%$ significance level are shaded.

northern edge of the cyclonic circulation may drive downward Ekman pumping that induces subduction of sea water. Furthermore, the downwelling oceanic Rossby wave generated by near-equatorial easterly anomalies can deepen the thermocline [30,32]. Both processes contribute to warm SST in that region, manifesting as a positive SST anomaly 
in the southwest Indian Ocean.

SST warming in the southwest Indian Ocean can further change spring surface winds. In spring (Figure 7(b)), anomalous cyclonic circulation appears in the region of warmer SST in winter, while anomalous anticyclonic circulation appears to its northeast. Such a distribution of anomalous surface winds is typical of a response to anti-symmetric heating [33]. Conversely, the surface wind anomalies influence local SST change. The Ekman upwelling associated with the cyclonic circulation anomaly dampens the downwelling Rossby wave underneath and consequently reduces SST warming in the southwest Indian Ocean, reflecting a negative feedback [34,35]. Furthermore, anomalous northwesterly winds off Sumatra and Java signify weakening southeasterly winds, since southeasterlies are prevalent in this region according to climatology. The weakened southeasterlies may induce warm coastal SST by reducing evaporation and increasing coastal downwelling [36,37].

In summer, the coastal SST anomaly further develops by the wind-evaporation-SST feedback mechanism [38,39]. That is, the south-to-north SST difference across the equator (increasing amplitude of the SST south of the equator is larger than that north of the equator) in spring may force a southward sea level pressure gradient, which would drive northerly winds. The Coriolis force turns these northerlies eastward (westward) to form northwesterlies (northeasterlies) south (north) of the equator (Figure 7(c)). The northwesterly wind anomaly south of the equator opposes the mean southeasterly winds over the Maritime Continent and thus reduces evaporation and increases coastal downwelling, further warming the local SST.

\section{Conclusion}

This study of the winter SST east of Australia and summer precipitation in the Yangtze River valley shows that there is a significant positive correlation between them. This correlation is well supported by the change of East Asian summer atmospheric circulations related to the variation of winter SST east of Australia. When the winter SST east of Australia is warmer than normal, the western Pacific subtropical high and the East Asian jet tend to shift southward the following summer, contemporaneous with anomalous low-level southwesterly winds prevailing over eastern China. These conditions are favorable for precipitation, and thus increase precipitation in the Yangtze River valley. The opposite situation is associated with colder winter SST east of Australia and reduces precipitation in the Yangtze River valley.

The underlying mechanism responsible for the influence of winter SST east of Australia on summer atmospheric circulations over East Asia is further described. It is found that winter SST anomaly east of Australia may impact the East Asian summer atmospheric circulation by its own per- sistence and by modulation of SST in the southern Indian Ocean. When the SST east of Australia is warmer in winter, it may persist until summer when it can affect the intensity and location of the western Pacific subtropical high via the inter-hemispheric teleconnection. This effect augments precipitation in the Yangtze River valley. Winter SST warming east of Australia is also accompanied by higher SST in the southwest Indian Ocean. The SST change in these two regions is linked by the atmospheric teleconnection wave train. The abnormal SST signal in the southwest Indian Ocean develops eastward with time because of local air-sea interaction, causing the SST in the Maritime Continent to warm in summer. The SST warming in the Maritime Continent can further affect East Asian atmospheric circulation and precipitation through its impact on convection. The identified mechanism is but one candidate; others may contribute to the observed link between the SST anomalies and Yangtze valley precipitation, given the complexity of air-sea interactions. Thus, more in-depth analyses based on quantitative diagnoses and state-of-the-art climate models are needed.

This work was supported by the Special Fund for Public Welfare Industry (Meteorology) (GYHY200906018), the National Natural Science Foundation of China (40805029) and the National Basic Research Program of China (2009CB421407 and 2010CB950304).

1 Gong D Y, Zhu J H, Wang S W. Significant relationship between spring $\mathrm{AO}$ and the summer rainfall along the Yangtze River. Chinese Sci Bull, 2002, 47: 546-549

2 Gong D Y, Ho C H. Arctic Oscillation signals in the East Asian summer monsoon. J Geophys Res, 2003, 108: 4066, doi: 10.1029/ 2002JD002193

3 Wang H J. Characteristic of the atmospheric general circulation in three flood years in China (in Chinese). Quart J Appl Meteorol, 2000, 11: 79-86

4 Wang H J, Matsuno T, Kurihara Y. Ensemble Hindcast Experiments for the flood period over China in 1998 by use of the CCSR/NIES Atmospheric General Circulation Model. J Meteorol Soc Jpn, 2000, 78: $357-365$

5 Zhao P, Zhou Z J, Liu J P. Variability of Tibetan spring snow and its associations with the hemispheric extratropical circulation and East Asian summer monsoon rainfall: A observational investigation. J Clim, 2007, 20: 3942-3955

6 Zhao P, Zhang X D, Zhou X J, et al. Sea-ice extent anomaly in the North Pacific and its impact on the East Asian summer monsoon rainfall. J Clim, 2004, 17: 3434-3447

7 Zhou B T, Wang H J. Relationship between the boreal spring Hadley circulation and the summer precipitation in the Yangtze River valley. J Geophys Res, 2006, 111: D16109, doi:10.1029/2005JD007006

8 Zhou B T, Cui X. Modeling the relationship between spring Hadley circulation and the summer precipitation in the Yangtze River valley (in Chinese). Clim Environ Res, 2008, 13: 182-188

$9 \mathrm{Xu} \mathrm{H} \mathrm{M,} \mathrm{He} \mathrm{J} \mathrm{H,} \mathrm{Guan} \mathrm{Z} \mathrm{Y,} \mathrm{et} \mathrm{al.} \mathrm{Possible} \mathrm{way} \mathrm{of} \mathrm{the} \mathrm{effect} \mathrm{of} \mathrm{WA}$ teleconnection pattern on the early summer monsoon over eastern Asia (in Chinese). Nanjing Inst Meteorol, 2000, 23: 361-369

10 Sun S Q, Sun B M. The relationship between the anomalous winter monsoon circulation over East Asia and summer drought/flooding in the Yangtze and Huaihe River valley (in Chinese). Acta Meteorol Sin, 1995, 53: 438-450

11 Chen W, Graf H F, Huang R H. The interannual variability of East Asian winter monsoon and its relation to the summer monsoon. Adv Atmos Sci, 2000, 17: 48-60 
12 Xue F, Wang H J, He J H. Interannual variability of Mascarene high and Australian high and their influences on East Asian summer monsoon. J Meteorol Soc Jpn, 2004, 82: 1173-1186

13 Wang H J, Fan K. Central-north China precipitation as reconstructed from the Qing dynasty: Signal of the Antarctic Atmospheric Oscillation. Geophys Res Lett, 2005, 32: L24705, doi:10.1029/2005GL024562

14 Fan K. Atmospheric circulation anomalies in the Southern Hemisphere and summer rainfall over Yangtze River Valley (in Chinese). Chin J Geophys, 2006, 49: 672-679

15 Sun J Q, Wang H J, Yuan W. A possible mechanism for the co-variability of the boreal spring Antarctic Oscillation and the Yangtze River valley summer rainfall. Int J Climatol, 2009, 29: 1276-1284

16 Gao H, Xue F, Wang H J. Influence of interannual variability of Antarctic oscillation on mei-yu along the Yangtze and Huaihe River valley and its importance to prediction. Chinese Sci Bull, 2003, 48(Supp II): 61-67

17 Fan K, Wang H J, Choi Y J. A physically-based statistical forecast model for the middle-lower reaches of the Yangtze River Valley summer rainfall. Chinese Sci Bull, 2008, 53: 602-609

18 Xue F, Wang H J, He J H. Interannual variability of Mascarene High and Australian High and their influence on the East Asian summer rainfall over East Asia. Chinese Sci Bull, 2003, 48: 492-497

19 Zhou B T, Cui X. Sea surface temperature east of Australia: A predictor of tropical cyclone frequency over the western North Pacific? Chinese Sci Bull, 2011, 56: 196-201

20 Liu G, Zhang Q Y, Sun S Q. The relationship between circulation and SST anomaly east of Australia and the summer rainfall in the middle and lower reaches of the Yangtze River (in Chiese). Chin J Atmos Sci, 2008, 32: 231-241

21 Kalnay E, Kanamistu M, Kistler R, et al. NCEP/NCAR 40-year reanalysis project. Bull Am Meteorol Soc, 1996, 77: 437-471

22 Smith T M, Reynolds R W. Improved Extended Reconstruction of SST (1854-1997). J Clim, 2004, 17: 2466-2477

23 Zhang Q Y, Tao S Y, Chen L T. The interannual variability of East Asian summer monsoon indices and its association with the pattern of general circulation over East Asia (in Chinese). Acta Meteorol Sin, 2003, 61: 559-568

24 Liang X Z, Wang W C. Association between China monsoon rainfall and tropospheric jets. Q J R Meteorol Soc, 1998, 124: 2597-2623
25 Lau K M, Kim K M, Yang S. Dynamical and boundary forcing characteristics of regional components of the Asian summer monsoon. $\mathrm{J}$ Clim, 2000, 13: 2461-2482

26 Liu G, Ji L R, Sun S Q, et al. An inter-hemispheric teleconnection and a possible mechanism for its formation. Adv Atmos Sci, 2010, 27: 629-638

27 Nitta T. Convective activities in the tropical western Pacific and their impact on Northern Hemisphere summer circulation. J Meteorol Soc Jpn, 1987, 65: 373-390

28 Huang R H, Sun F Y. Impact of the tropical western Pacific on the East Asian summer monsoon. J Meteorol Soc Jpn, 1992, 70: 243-256

29 Klein S A, Soden B, Lau N C. Remote sea surface temperature variations during ENSO: Evidence for a tropical atmospheric bridge. J Clim, 1999, 12: 917-932

30 Xie S P, Annanalai H, Schott F A, et al. Structure and mechanisms of South Indian Ocean climate variability. J Clim, 2002, 15: 864-878

31 Yu L, Jin X Z, Weller R A. Annual, seasonal, and interannual variability of air-sea heat fluxes in the Indian Ocean. J Clim, 2007, 20: 3190-3209

32 Huang B, Kinter III J L. Interannual variability in the tropical Indian Ocean. J Geophys Res, 2002, 107: 3199, doi:10.1029/2001JC001278

33 Wu R G, Kirtman B P, Krishnamurthy V. An asymmetric mode of tropical Indian Ocean rainfall variability in boreal spring. J Geophys Res, 2008, 113: D05104, doi: 10.1029/2007JD009316

34 Philander S G H, Yamagata T, Pacanowski R C. Unstable air-sea interactions in the Tropics. J Atmos Sci, 1984, 41: 604-613

35 Hirst A C. Unstable and damped equatorial modes in simple coupled ocean-atmosphere models. J Atmos Sci, 1986, 43: 606-630

36 Saji N H, Goswami B N, Vinayachandran P N, et al. A dipole mode in the tropical Indian Ocean. Nature, 1999, 401: 360-363

37 Murtugudde R, McCreary J P, Busalacchi A J. Oceanic processes associated with anomalous events in the Indian Ocean with relevance to 1997-1998. J Geophys Res, 2000, 105: 3295-3306

38 Xie S P, Philander S G H. A coupled ocean-atmosphere model of relevance to the ITCZ in the eastern Pacific. Tellus, 1994, 46A: 340-350

39 Chang P, Ji L, Li H. A decadal climate variation in the tropical Atlantic Ocean from thermodynamics air-sea interactions. Nature, 1997, 385: $516-518$

Open Access This article is distributed under the terms of the Creative Commons Attribution License which permits any use, distribution, and reproduction in any medium, provided the original author(s) and source are credited. 